\title{
Electrocommunication and Social Behaviour in Marcusenius senegalensis (Mormyridae, Teleostei)
}

\author{
ANDREAS SCHEFFEL \& BERND KRAMER
}

SCHEFFEL, A. \& KRAMER, B. 1997: Electrocommunication and social behaviour in Marcusenius senegalensis (Mormyridae, Teleostei). Ethology 103, $404-420$.

\begin{abstract}
The electric organ discharges (EODs) of Marcusenius senegalensis, a West African freshwater fish, are bipolar pulses of short duration $(220 \pm \mathrm{SE} 13 \mu \mathrm{s})$. In males $(\mathrm{n}=10 ; 10.1-13.1 \mathrm{~cm}$ standard length - which is around the size of getting mature), the duration of EOD pulses was of significantly greater variance than in females $(n=9$; 9.8-12.8 cm standard length). Male EODs also showed a tendency for a longer duration than female EODs.

Groups of three as well as of $14 \mathrm{M}$. senegalensis formed temporary schools in a 'naturally' equipped 720-1 tank. While swimming slowly in a loose school during their nocturnal active phase, fish discharged in irregular long-short-long inter-EOD interval patterns. Near neighbours displayed a tendency to discharge in intervals of similar duration (nearest neighbour distance $<\frac{1}{2}$ fish length).

On removal of a plastic partition that had separated a pair of fish for at least 3 days, mutual threat displays followed by fighting were observed. During threatening, the fish alternated regularly between bursts of a high discharge rate and short discharge breaks; the rate of change was $4 / \mathrm{s}$.

The subdominant animal in a group of two was attacked frequently and often ceased discharging when the dominant fish approached. Courtship behaviour involving gonadally mature fish was accompanied by highdischarge-rate displays with intervals of constant duration in both fish, and the reciprocal display of 'preferred' EOD latencies in the $12 \mathrm{~ms}$ range.

The results demonstrate electric communication by distinct inter-discharge interval patterns in the social behaviour of this mormyrid fish.

Corresponding author: Bernd KRAMER, Zoologisches Institut der Universität Regensburg, D-93040 Regensburg, Germany. E-mail: Bernd.Kramer@Biologie.uni-regensburg.de
\end{abstract}

\section{Introduction}

Marcusenius senegalensis belongs to the family Mormyridae, which is the most speciose freshwater fish family endemic to Africa, including at least 188 species and 18 genera (GOSSE 1984; LÉVÊQUE et al. 1990). All species that have been examined generate brief electric organ discharges (EODs) of weak amplitude, separated by variable interdischarge intervals (LISSMANN 1958; HOPKINS 1988; MOLLER 1995). These interval patterns enable mormyrids to communicate during social interactions (reviews KRAMER 1990, 1994, 1996). A communication function of special interval patterns was demonstrated in play-back experiments (KRAMER 1979), and interval patterns enable mormyrids to recognize conspecifics (KRAMER \& LÜCKER 1990; KRAMER \& KUHN 1994). The inter-discharge 
interval (IDI) code of naturally interacting mormyrids has been examined in only a few species, in most cases involving isolated fish or pairs of fish in small aquaria. The aim of the present investigation is to study electrocommunication by the interval-code in groups of fish in 'naturally' equipped, truly big aquaria that allowed spacing of fish and migration of a school (some specific aspects of behaviour were studied in pairs of fish using smaller aquaria). Thus we were able to consider additional aspects of social behaviour, such as schooling behaviour that has not been examined before with regard to discharge interval patterns for naturally free-swimming mormyrid groups. We used Marcusenius senegalensis, a common species in West Africa the IDI code of which has not been studied before.

We also analysed the EOD waveforms of all individuals for differences between the sexes that have been suggested to exist in several mormyrid species (reviews HOPKINS 1988; KRAMER 1994; LANDSMAN 1995).

\section{Methods}

Twenty-one Marcusenius senegalensis (Steindachner) from West Africa were commercially obtained and the species identity determined using the key by LÉVÊQUE et al. (1990).

The animals were exposed to a $12 \mathrm{~h} / 12 \mathrm{~h}$ light-dark cycle including a short dusk period between the dark and the light phase; they were alternately fed with deep-frozen Chironomus larvae and eggs from carps. Because of strong intraspecific aggression we kept fish singly in $45-1$ tanks at $26.5-29^{\circ} \mathrm{C}$ when not studied. Water conductivity was held between 100 and $150 \mu \mathrm{S} / \mathrm{cm}$ by weekly partial water exchange with deionized water. All experiments were performed at $27.5 \pm 0.3{ }^{\circ} \mathrm{C}$ and $100 \pm 5 \mu \mathrm{S} / \mathrm{cm}$. The electric organ discharges of each fish were recorded in a $120-\mathrm{l}$ tank with an isolated fish resting in a ceramic tube. The potential difference between head and tail was measured by a pair of carbon electrodes using a wide-band preamplifier $(1-100000 \mathrm{~Hz}$; variable gain $10 \times$ to $100 \times$ ). The output was digitized and stored on computer disc. A second set of samples was taken half a year later. A dramatic change in mormyrid discharge waveform can be evoked by a strong change in water conductivity (BELL et al. 1976; BRATTON \& KRAMER 1988); the EOD waveform recovers within 2 d (KRAMER \& KUHN 1993). Therefore, fish were kept in water of the exact recording conductivity for at least $2 \mathrm{~d}$ before digitizing their EOD waveforms. Several waveform parameters were tested for significant differences between the sexes using the t-test including its modification by Welch (LORENZ 1988; p. 170), and the F-test (software package InStat). Two fish were excluded from these tests: one fish (no. 15) had died and decomposed and was thus not available for histological distinction of the sex, and the other one (no. 12) was a single fish that had been obtained from a different dealer, and represented perhaps another subspecies. This fish-although all anatomical characters were within the species' range-had somewhat bigger eyes and a lighter colour. There are three subspecies of Marcusenius senegalensis known from different areas of the Niger basin (GOSSE 1984).

The tested fish (10 males, 9 females) showed a sexual dimorphism in the shape of the base of their anal fin, which is straight in females and shows a kink in males. This was confirmed by gonad histology.

For nocturnal observation the aquaria were illuminated by infra-red light and the behaviour video-taped using an infra-red-sensitive camera. The discharges were recorded by two pairs of carbon electrodes connected to two differential preamplifiers, and separately stored on the audio-tracks of a video tape. The EODs stored on the audio tracks were transferred to photographic film using an oscilloscope camera (film speed, $1 \mathrm{~m} / \mathrm{s}$ past the open shutter). Individual discrimination of EODs was achieved by using differences in waveforms, amplitude or polarity.

First, the social behaviour in a group of 14 fish was studied in a $720-1$ tank $(60 \times 50 \times 240 \mathrm{~cm})$ with many 'natural' hiding places (stones, water plants and tree trunks). Later, discharge patterns within schooling behaviour were investigated in more detail in a group of three in the same tank. Although we excluded fish no. 12 from EOD waveform analysis, we did use this fish for observing social behaviour because it did not differ in interval patterns and behaviour. Fish no. 12 had an EOD of very short duration with a slightly more pronounced negative pre-phase than observed in the other fish; therefore, this fish was ideal for individual-specific EOD discrimination from recordings on magnetic tape. More stationary patterns of behaviour (e.g. threat displays and fights between non-familiar fish) were studied in groups of two in smaller tanks $(50 \times 50 \times 80 \mathrm{~cm})$. To observe courtship 
behaviour in selected pairs of fish (in tanks of $50 \times 50 \times 110 \mathrm{~cm}$ and $60 \times 60 \times 120$ ), water conductivity was reduced below $100 \mu \mathrm{S} / \mathrm{cm}$ and temperature raised up to $29^{\circ} \mathrm{C}$.

Following the completion of all behavioural experiments, fish were killed using the anaesthetic MS222 (Sigma Chemical Co.). The gonads were histologically examined and the species identity reexamined according to LÉVÊQUE et al. (1990).

\section{Results}

\section{Gonadal status}

The standard lengths of the juvenile fish $(9.8-12.8 \mathrm{~cm}$ for females, $10.1-13.1 \mathrm{~cm}$ for males) of the present study were much shorter than the maximum known species size (32.1 cm; LÉVÊQUE et al. 1990). Thus only two fish (nos 8 and 10) exceeded $40 \%$ of the maximum species size at which sexual maturity was reported to occur in field studies of several mormyrid species (Blake 1977; Kolding et al. 1992). But the rest of the group was not far from this limit.

Two months after conclusion of the study, males had fully developed testes with plenty of sperm and showed a kink in the anal fin base (that was weak in four males). Five females had mature ovaries (at least stage five; TAKASHIMA \& HIBIYA 1995) with oocytes of more than $1 \mathrm{~mm}$ in diameter. One female showed stage-two oocytes, and the remaining three females were at stage one.

\section{Waveform Analysis of the Electric Organ Discharge}

The EODs of all fish were biphasic in waveform with a head-positive phase followed by a head-negative one as has also been observed in other Marcusenius species (MOLLER et al. 1979; HOPKINS 1981; GRAFF 1989; KRAMER 1996). The EODs lasted 170-240 $\mu$ s (Table 1), except in two males (nos 10 and 17) with a pulse duration of almost $400 \mu \mathrm{s}$. Fig. 1a shows two EODs of long and of average duration.

Several EOD parameters (Fig. 1b) were analysed quantitatively (Tables 1, 2). The duration of phases was determined using a $2 \%$ deviation criterion from baseline $(100 \%$ corresponding to the peak-to-peak amplitude). The $\mathrm{P} / \mathrm{N}$ duration-ratio was higher for males than for females $(p<0.03)$ in the first series of recordings; however, this difference was not significant in the second series taken half a year later.

A clear difference between males and females that was consistent for both series of recordings was the significantly higher SD for male duration-specific EOD parameters $(\mathrm{p}<0.0005$; Table 2). These parameters were total EOD duration, duration of $\mathrm{P}$ and $\mathrm{N}$ phases, and the separation between positive and negative amplitude peaks. EOD parameters did not depend on standard length; a least-squares regression line was not significantly different from zero (no correlation).

\section{Social Behaviour}

In this nocturnal species, three kinds of social interaction were observed: schooling behaviour, fights, and interactions within hierarchically structured groups.

Schooling behaviour. Although constant hierarchies occurred in groups where the members were familiar with each other, they also formed temporary schools - especially in 
Table 1: Statistical comparison of various EOD waveform parameters in female $(\mathrm{n}=9)$ and male $(\mathrm{n}=10)$ Marcusenius senegalensis, shown as $\overline{\mathrm{X}} \pm$ SE. For explanation of EOD waveform parameters, see Fig. 2

\begin{tabular}{|c|c|c|c|c|c|c|c|}
\hline $\begin{array}{l}\text { Series of } \\
\text { recordings }\end{array}$ & $\begin{array}{c}\text { Total duration } \\
(\mu \mathrm{s})\end{array}$ & $\begin{array}{c}\text { P-phase } \\
\text { duration }(\mu \mathrm{s})\end{array}$ & $\begin{array}{c}\text { N-phase } \\
\text { duration }(\mu \mathrm{s})\end{array}$ & $\begin{array}{l}\text { Separation P- } \\
\text { to N-peak }(\mu \mathrm{s})\end{array}$ & $\begin{array}{l}\text { Duration } \\
\text { ratio } \mathrm{P} / \mathrm{N}\end{array}$ & $\begin{array}{l}\text { Amplitude } \\
\text { ratio } \mathrm{P} / \mathrm{N}\end{array}$ & $\begin{array}{l}\text { Area ratio } \\
\mathrm{P} / \mathrm{N}\end{array}$ \\
\hline \multicolumn{8}{|l|}{ First series } \\
\hline Females & $202 \pm 7$ & $122 \pm 4$ & $79.4 \pm 3.3$ & $46.8 \pm 1$ & $1.55 \pm 0.05$ & $0.717 \pm 0.007$ & $0.952 \pm 0.016$ \\
\hline Males & $236 \pm 23$ & $148 \pm 14$ & $88.3 \pm 9.9$ & $54.0 \pm 4$ & $1.71 \pm 0.06$ & $0.717 \pm 0.011$ & $0.977 \pm 0.012$ \\
\hline $\mathrm{p}$ (two-sided t-test) & $0.171^{1}$ & $0.085^{1}$ & $0.408^{1}$ & $0.108^{1}$ & 0.027 & 0.577 & 0.214 \\
\hline \multicolumn{8}{|l|}{ Second series } \\
\hline Females & $211 \pm 5$ & $130 \pm 4$ & $81.4 \pm 1.5$ & $48.8 \pm 0.7$ & $1.596 \pm 0.032$ & $0.727 \pm 0.012$ & $0.940 \pm 0.008$ \\
\hline Males & $239 \pm 5$ & $148 \pm 11$ & $91.6 \pm 8$ & $54.9 \pm 4.4$ & $1.632 \pm 0.046$ & $0.717 \pm 0.011$ & $0.927 \pm 0.013$ \\
\hline $\mathrm{p}$ (two-sided $\mathrm{t}$-test) & $0.171^{1}$ & $0.144^{1}$ & $0.242^{1}$ & $0.201^{1}$ & 0.536 & 0.560 & 0.396 \\
\hline
\end{tabular}

${ }^{1}$ Welch's modification of the t-test was used when SD differed significantly from each other.

Table 2: Statistical comparison of the SD of various EOD parameters (Table 1) for males and females using the F-test

\begin{tabular}{|c|c|c|c|c|c|c|c|}
\hline $\begin{array}{l}\text { Series of } \\
\text { recordings }\end{array}$ & $\begin{array}{l}\text { Total duration } \\
\qquad(\mu \mathrm{s})\end{array}$ & $\begin{array}{c}\text { P-phase } \\
\text { duration }(\mu \mathrm{s})\end{array}$ & $\begin{array}{c}\text { N-phase } \\
\text { duration }(\mu \mathrm{s})\end{array}$ & $\begin{array}{l}\text { Separation P- } \\
\text { to N-peak }(\mu \mathrm{s})\end{array}$ & $\begin{array}{l}\text { Duration } \\
\text { ratio } \mathrm{P} / \mathrm{N}\end{array}$ & $\begin{array}{l}\text { Amplitude } \\
\text { ratio } \mathrm{P} / \mathrm{N}\end{array}$ & $\begin{array}{c}\text { Area ratio } \\
\mathrm{P} / \mathrm{N}\end{array}$ \\
\hline First series & $\begin{array}{l}p=0.0004 \\
F=14.777\end{array}$ & $\begin{array}{l}\mathrm{p}=0.0003 \\
\mathrm{~F}=17.054\end{array}$ & $\begin{array}{l}p=0.0016 \\
F=10.205\end{array}$ & $\begin{array}{l}\mathrm{p}=0.0003 \\
\mathrm{~F}=16.377\end{array}$ & $\begin{array}{l}\mathrm{p}=0.241 \\
\mathrm{~F}=1.669\end{array}$ & $\begin{array}{l}\mathrm{p}=0.0692 \\
\mathrm{~F}=2.984\end{array}$ & $\begin{array}{l}\mathrm{p}=0.2141 \\
\mathrm{~F}=1.736\end{array}$ \\
\hline Second series & $\begin{array}{l}\mathrm{p}=0.0002 \\
\mathrm{~F}=17.945\end{array}$ & $\begin{array}{l}\mathrm{p}=0.0014 \\
\mathrm{~F}=10.747\end{array}$ & $\begin{array}{l}\mathrm{p}<0.0001 \\
\mathrm{~F}=31.906\end{array}$ & $\begin{array}{l}\mathrm{p}<0.0001 \\
\mathrm{~F}=43.054\end{array}$ & $\begin{array}{l}\mathrm{p}=0.124 \\
\mathrm{~F}=2.329\end{array}$ & $\begin{array}{l}\mathrm{p}=0.5038 \\
\mathrm{~F}=1.003\end{array}$ & $\begin{array}{l}\mathrm{p}=0.0851 \\
\mathrm{~F}=2.742\end{array}$ \\
\hline
\end{tabular}



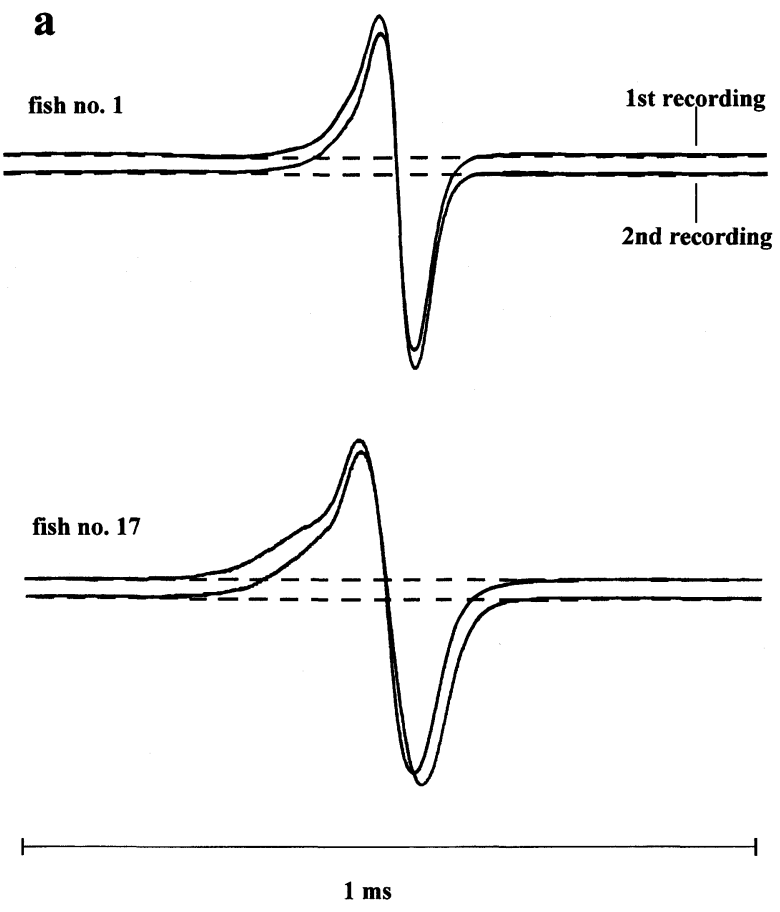

b

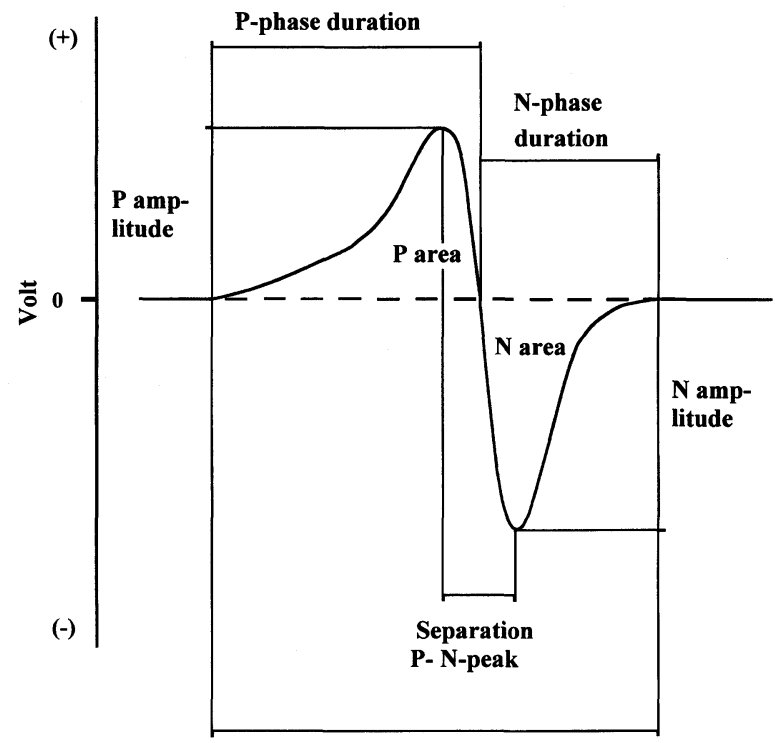

total duration

Fig. 1: a. Intraspecific variability and individual long-term stability in the EOD -waveform of selected Marcusenius senegalensis. Ordinate (not shown), linear voltage, with dashed baseline = zero volts; head-positive is upwards. Abscissa, time; Fish no. 17 had the EOD of longest duration; the EOD of no. 1 was of average duration. First and second recordings were separated by half a year. b. Waveform parameters of an EOD, as used for the analyses in Tables 1 and 2. Ordinate, linear amplitude in volts; head-positivity is upwards. Abscissa, time 
groups of a large size. Typical schooling behaviour was shown by a group of 14 in a 720 1 tank. During the day most members of the group rested between dense plant material in one corner of the aquarium. Some of the larger individuals were distributed all over the tank, having found cover in isolated, dark hiding places. After presentation of food in the middle of the light phase, the fish tended to form close associations, foraging at the bottom. These compact schools slowly migrated in one direction with individual fish moving forward in succession, and stopping to forage again (Fig. 2a). The inter-individual distances within the group were extremely small (fish almost touching each other). When one fish darted back to cover, the others would follow one by one with little delay. These
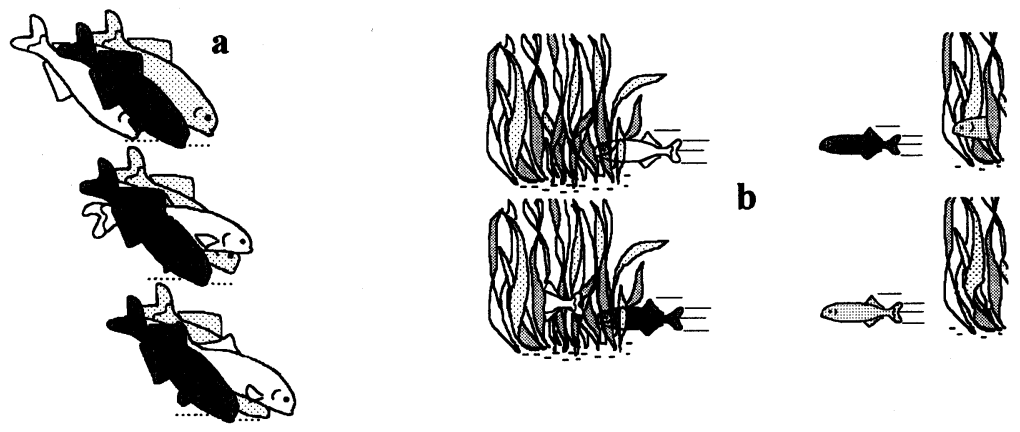

b
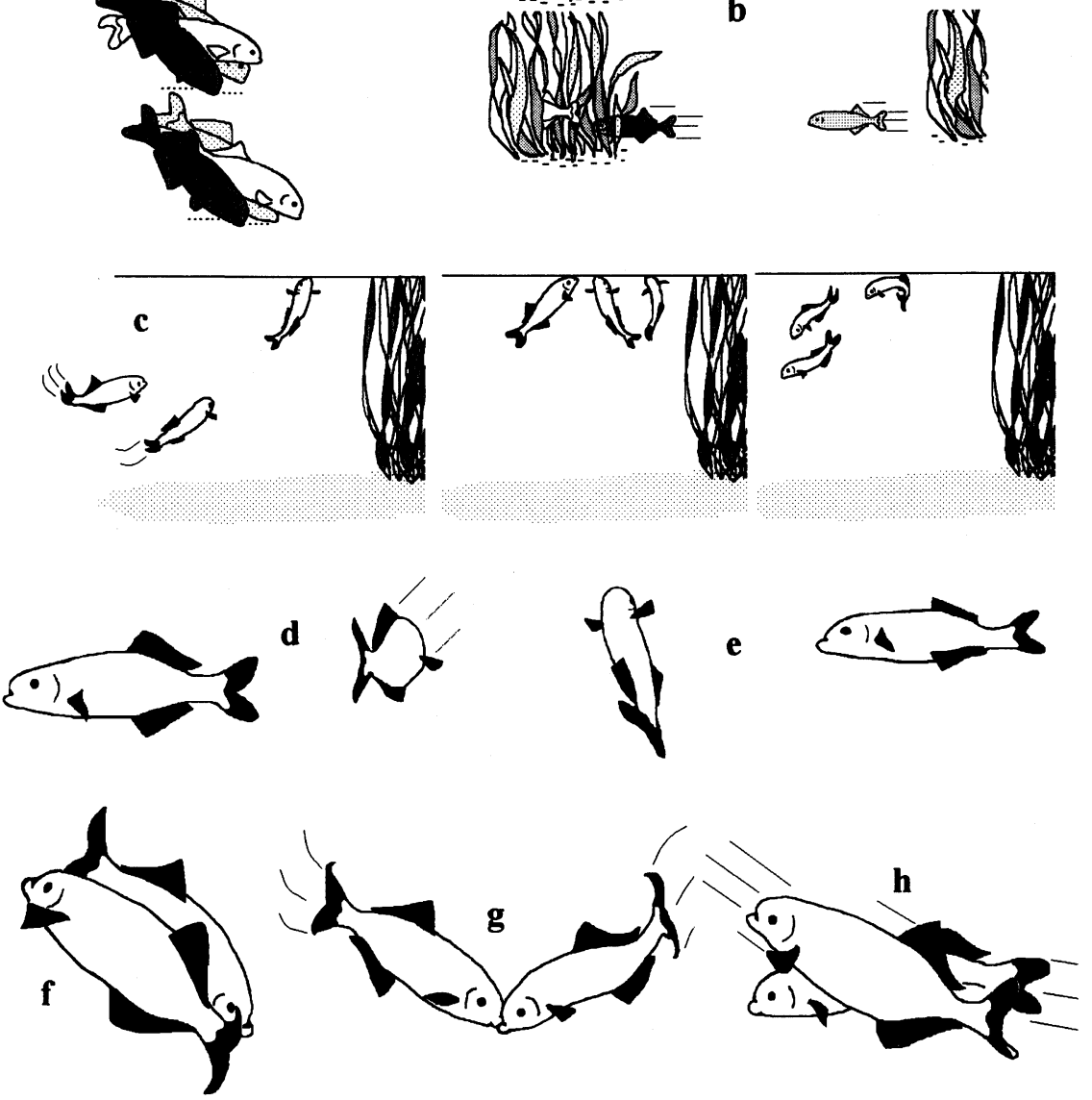

Fig. 2: Typical social interactions of Marcusenius senegalensis.: a. movement of a compact foraging school (three frames separated by $0.5 \mathrm{~s}$ ), b. one-by-one swimming of a group, c. surface-floating school, d. initial approaching phase before a fight, e. distance threat, f. antiparallel display, g. mouth fight, h. courtship behaviour 
excursions during daytime usually lasted less than $20 \mathrm{~s}$ and were repeated about every minute but became less frequent after about $30 \mathrm{~min}$. To visit more distant places, the animals darted through open water one by one, following the leading fish within a short distance and gathering in shelters such as plant groups (Fig. 2b). There they again formed a close foraging school. Individual fish resting in the immediate surroundings often joined these schools.

During dusk lasting about $10 \mathrm{~min}$, a compact group searched for food at the bottom, without returning to the shelter. At the beginning of the dark phase the school left the bottom. During the first nocturnal minutes, a group behaviour defined as 'surface-floating' was observed (Fig. 2c). The animals assumed a vertical position (snout at the water surface) by quick strokes of the tail fin, slowly drifting along the surface. Mostly this behaviour was initiated by a single fish or a small group of fish. Within a short time $(\approx 2 \mathrm{~s})$ almost all members of a school with individual distances of less than one fish length gathered at the surface. There was no uniform direction for floating. Individuals briefly diving and surfacing again at other places caused slow drifting of the school. The whole group returned to the bottom after a few minutes. Temporary interruptions of this group behaviour of surfacefloating were mostly initiated by the spontaneous diving of a single fish.

After about $20 \mathrm{~min}$ the school of 14 became looser (nearest neighbour distance $>1$ fish length) and individuals more independent of each other. But temporarily they still formed small or large groups for foraging, or for moving through mid-water. Neither during dusk nor during night were fish as shy as during daytime, when they darted oneby-one from shelter to shelter.

We examined the discharge patterns during periods of behaviour resembling schooling behaviour, mainly in a group of three (fish nos 12, 15 and 20). Surface-floating was not observed in such small groups. During daytime the group of three was shyer than larger groups, and the fast one-by-one swimming, as well as foraging, occurred only under reduced illumination and less frequently. Often only two fish were involved in darting from shelter to shelter; they followed each other at distances within 2-3 fish lengths at a speed of $20-30 \mathrm{~cm} / \mathrm{s}$, and discharged at short, regular intervals $(17 \pm \mathrm{SD} 3 \mathrm{~ms})$. This agreed well with the interval duration that was determined in darting fish from a group of 14 (16 $\pm \mathrm{SD} 2 \mathrm{~ms}$ ). In agreement with earlier observations, at such high discharge rates no preferred discharge latency (Bauer \& Kramer 1974; review Kramer 1990) was seen.

Discharge patterns during daytime foraging (Fig. 3) were similar to those observed during daytime 'one-by-one swimming', but were less regular ( $23 \pm \mathrm{SD} 7 \mathrm{~ms}$ ). Moving slowly $(<10 \mathrm{~cm} / \mathrm{s})$ within a loose association, individual fish showed irregular long-shortlong patterns during the dark phase. Similar patterns occurred when isolated fish displayed comparable behaviour during night. The average intervals were of much longer duration than during daytime activity (Fig. 4). Near neighbours showed the tendency to match their range of interval variation to each other. Fish passing by each other at very close distance synchronized their discharge intervals for brief periods of time. In one case a preferred latency of about $10 \mathrm{~ms}$ was recorded (Fig. 4, arrows).

Fights. Staged encounters of two $M$. senegalensis that were not familiar with each other usually implied fights. After removal of a plastic partition separating two fish the rivals usually approached each other cautiously. They often showed backward swimming, short 

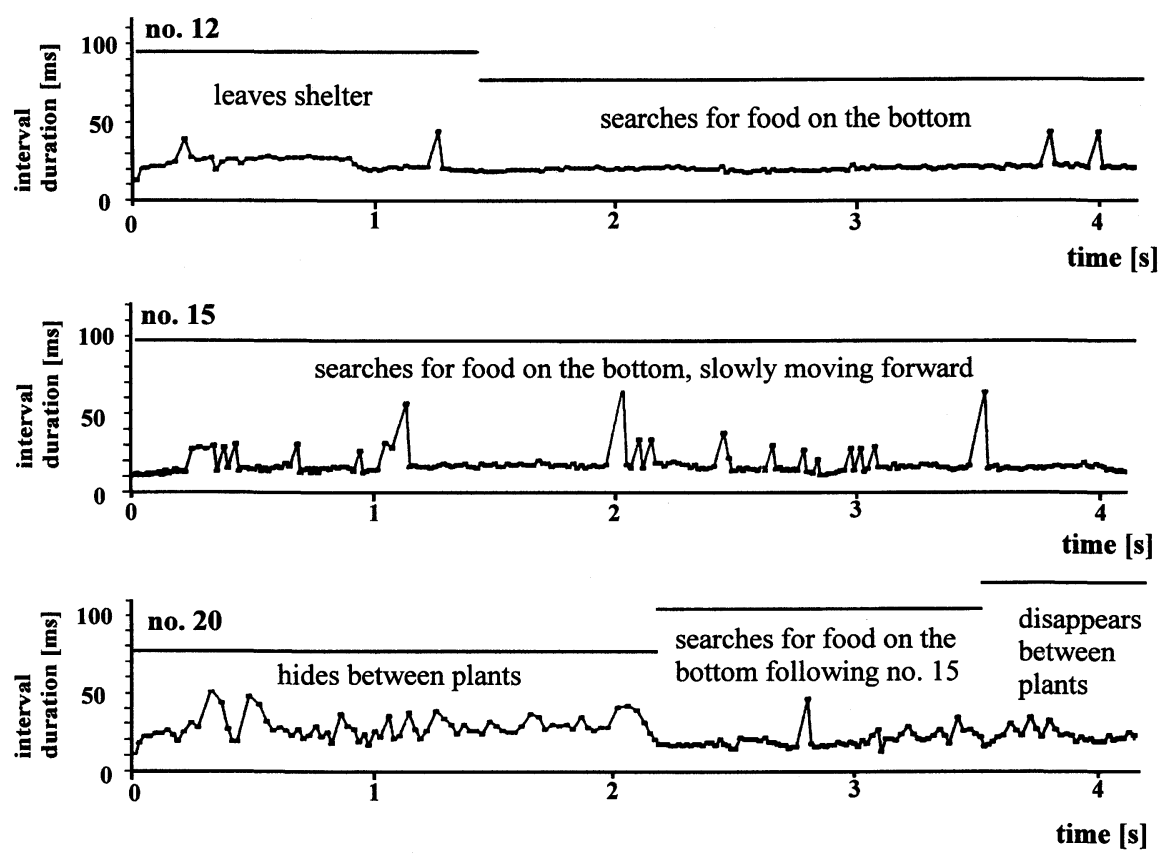

Fig. 3: Concurrent discharge activities of three Marcusenius senegalensis foraging together during day-time (fish nos. 12, 15 and 20). Ordinate: duration of individual interdischarge intervals [ms], abcissa: time [s]

stops, pulling backwards and forwards repeatedly (Fig. 2d). This initial phase of a few seconds did not always occur exactly in this form, e.g. when fish alternated between fighting and threat displays in overt aggression.

When displaying the distance threat (Fig. 2e), a fish stood in mid-water assuming a rigid posture, and keeping a distance of at least 0.5 fish length from the opponent. During this phase fish often tilted sideways (up to $45^{\circ}$ ).

Antiparallel display (Fig. 2f) has been described for some other mormyrid species, e.g. Gnathonemus petersii (BELL et al. 1974; KRAMER 1974; KRAMER \& BAUER 1976). A pair of M. senegalensis, orientated antiparallel to each other, often rotated slowly around a common centre. The axis of this rotation movement sometimes was not vertical but tilted. Often this display alternated with short bead-to-tail circling. Here both fish tried to attack the rival's tail. Also distance threat could be followed by fights. In mouth fights (Fig. 2g), one of the animals attacked the head of the other which tried to fence off this attack with its mouth and to push back the attacker. Short series of reciprocal bites arose from this situation. Bites were restricted to the head region. Biting bouts lasted 1-2 s. Parallel display (with heads facing in the same direction) occurred very rarely. Conflicts ended after a few minutes when one fish tried to escape; it was chased by the dominant one. The defeated fish actively avoided the winner.

Three kinds of conflict-typical discharge patterns were recorded. (1) The initial approaching phase was accompanied by series of rather constant intervals between 20 and 

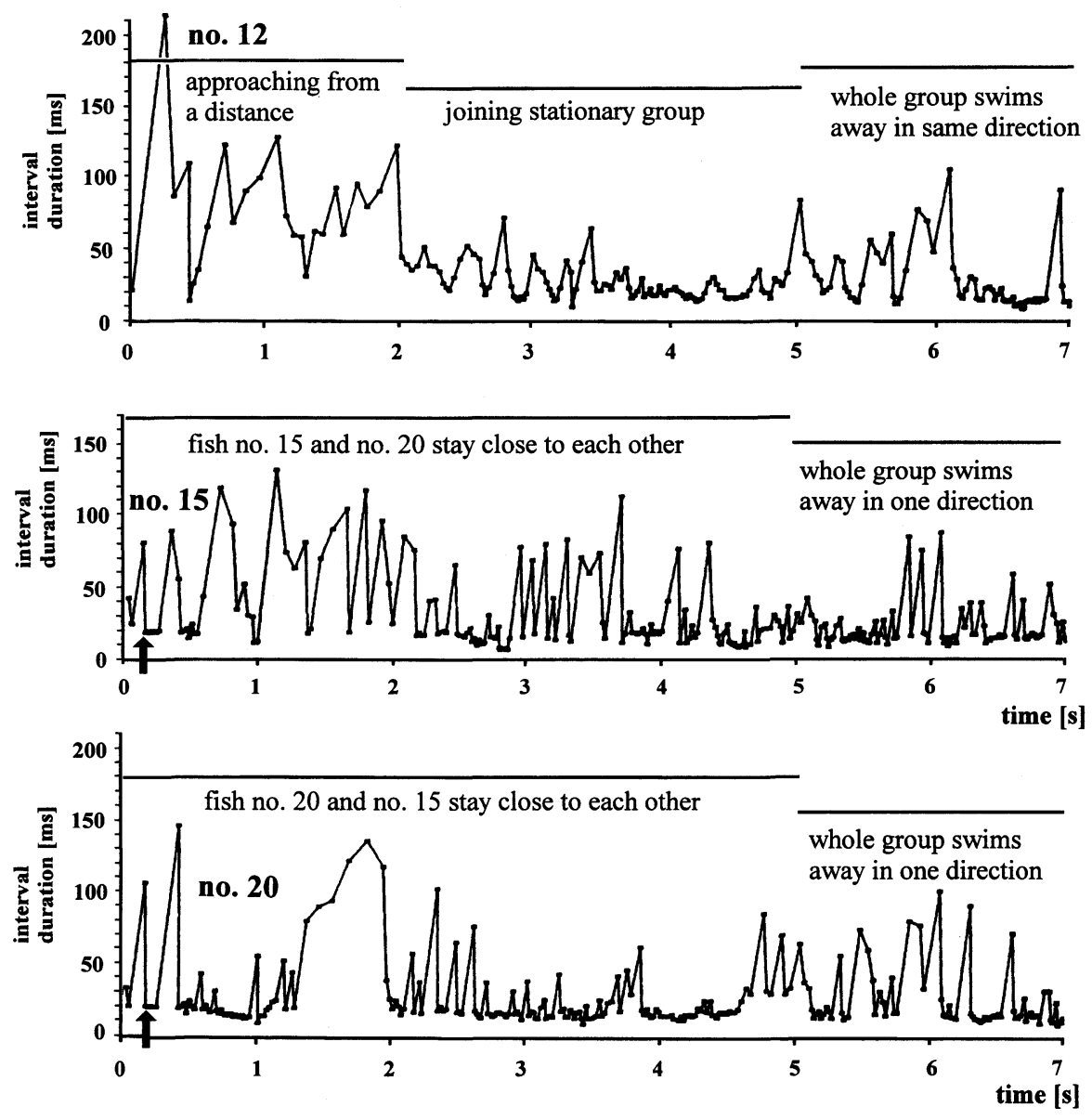

Fig. 4: Concurrent discharge activities of three Marcusenius senegalensis passing each other within short distances and forming a compact school moving together in the same direction during the dark phase (fish nos. 12, 15 and 20). Arrows: synchronizsation of interval pattern and preferred latencies between fish no. 15 and no. 20. Ordinates and abscissae as in Fig. 3

$40 \mathrm{~ms}$ (Fig. 5). (2) During threat displays, at least one of the rivals discharged in bursts of short intervals (repeated at a rate of $4-5$ per second) separated by longer intervals ( $>50 \mathrm{~ms}$ ). The bursts consisted of 7-8 intervals from 9 to $14 \mathrm{~ms}$ and showed a tendency of intervals to increase in duration. Often the bursts were framed by intervals of medium duration $(20-30 \mathrm{~ms})$. The threat patterns shown by the other fish were similar but often more variable. The change from the fairly static (with fish moving little) threat displays to more mobile interactions like attack intentions or overt fight was accompanied by (3) intervals of short duration; long intervals between threat bursts disappeared. Especially after prolonged threatening, the repetitive burst element was also observed during fights. The long interburst intervals, however, were replaced by a few shorter intervals of 30-50 ms (see Fig. 5, 
no. 11 meets no. 17
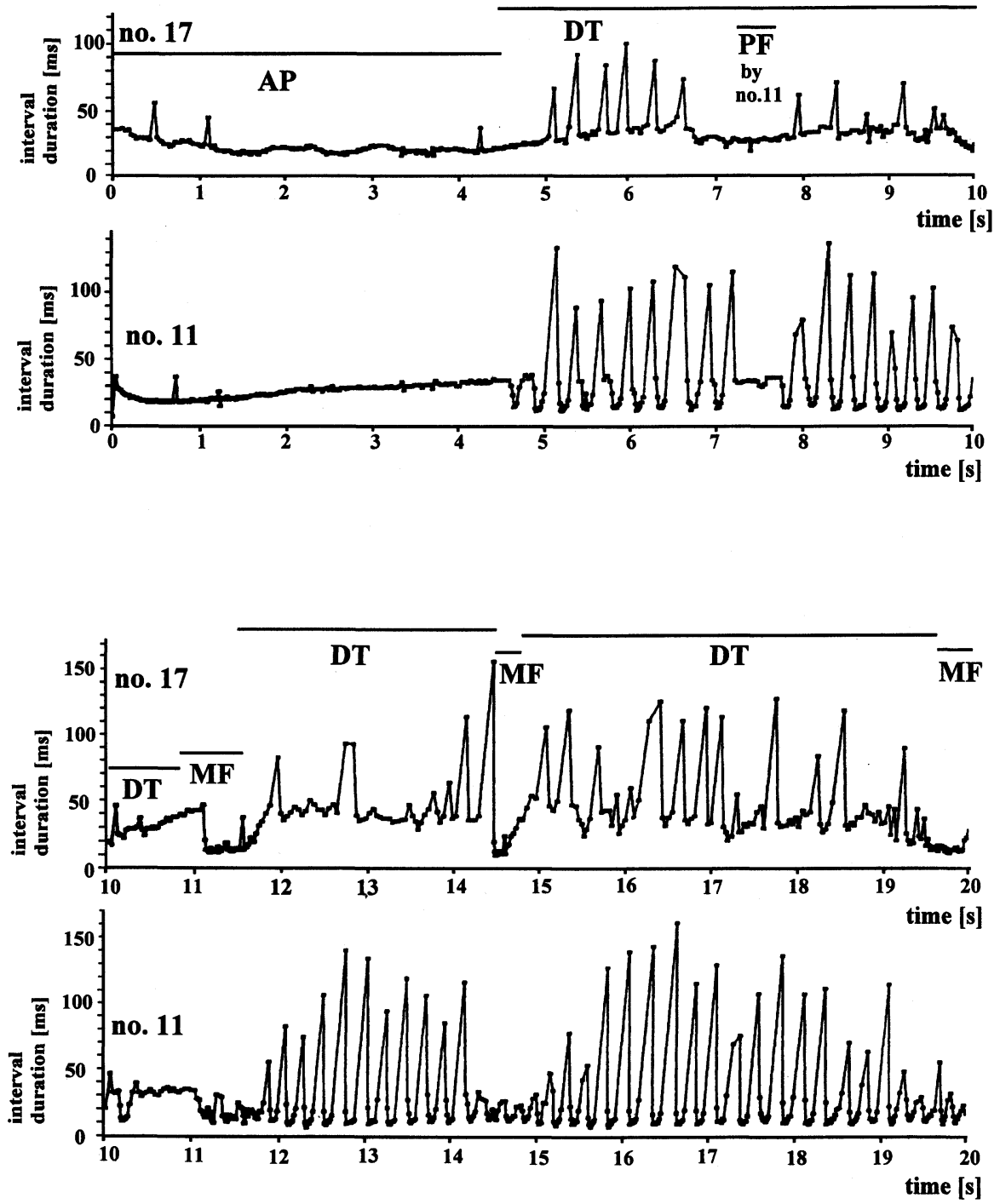

Fig. 5: Concurrent discharge activities during aggression between Marcusenius senegalensis that were unfamiliar to each other (no. 11 meets no. 17), including threat and fight displays. AP = approaching phase; DT = distance threat; $\mathrm{MF}=$ mouth-fighting; $\mathrm{PF}=$ pushing forward by one fish (no real attack). Ordinates and abscissae as in Fig. 3

14th to 15th second, fish no. 11). The change of interval patterns was not exactly synchronized with a change in motor displays: for example, long inter-burst intervals sometimes vanished half a second before a fight began, or just occurred again $\frac{1}{2} \mathrm{~s}$ after returning to typical threat behaviour. 
Hierarchically structured groups. In groups of two with members familiar to each other, a hierarchy was apparent. Especially two such groups including a male (fish no. 3; $126 \mathrm{~mm}$; with a distinct kink of the anal fin base, a good indicator of the male sex in mormyrids) and a large female (fish no. 21; $124 \mathrm{~mm}$; no kink) in each case were examined. In both groups the male was dominant over the female. During day the animals rested in preferred shelters well separated from each other, leaving only for feeding. At the beginning of the dark phase they came out to forage together. After a few min, slight aggression from the male caused avoidance behaviour by the submissive female. The attacks by the male became stronger after 10-20 min. The female responded by briskly swimming away. From this time on it avoided the male by escaping early to remote corners behind big objects.

One night we observed two short interactions that were free of any aggression or flight behaviour. Both fish swam closely around each other within a distance of less than one fish length, repeatedly pushing forward and backward (Fig. $2 \mathrm{~h}$ ). These short displays probably represented courtship behaviour, because the involved fish were definitely mature as ascertained by subsequent gonad histology (plenty of sperm and fully developed testicular canals up to $118.4 \mu \mathrm{m}$ wide; ovary with fully developed oocytes of around $1.13 \mathrm{~mm}$ in diameter, of at least stage five). Both discharge sequences were followed by intense attacks of the male directed towards the female.

Fast motor acts during attack and flight behaviour were accompanied by highfrequency discharge-bursts (intervals of about $15 \mathrm{~ms}$ ). Comparable bursts were also recorded when isolated fish performed sharp turns or accelerations. Contact avoidance by the females in both groups was accompanied by discharge cessation. The subdominant females discharged only during certain activities like foraging or closely passing by an object - when the male was not in the immediate vicinity. As soon as a female began discharging, the male came closer displaying high-frequency patterns. Shortly before contact both fish stopped discharging. The female tried to escape, remaining 'electrically silent' for some while. The male, however, resumed discharging at a high frequency after about $1 \mathrm{~s}$, obviously searching for the female (Fig. 6). Swimming around each other at close distance (presumed courtship behaviour) was accompanied by very regular sequences of intervals of about $20 \mathrm{~ms}$ (Fig. 7). For $2 \mathrm{~s}$ (from 4 to $6 \mathrm{~s}$ in Fig. 7), both fish locked into the same discharge rate and mutually showed a preferred discharge latency of 9-12 ms to the EODs of the other (Fig. 8). This involved about 40 EODs for each fish.

\section{Discussion}

The analysis of EOD waveform of our Marcusenius senegalensis showed differences between the two sexes as apparent from the significantly greater variance in all duration parameters (P-phase-, N-phase-, total pulse- and peak-to-peak durations) in males compared with females. As stated in Results, only two of our fish (male no. 10 with a long pulse and male no. 8 with a pulse of average duration) exceeded the minimum size at which sexual maturity occurs in natural populations of several other mormyrid species, that is, about $40 \%$ of the maximal size for that species. However, the smaller males were also sexually mature and showed a (sometimes only weak) kink in the anal fin base, and their growth in size may have been slowed by captivity without preventing them from becoming sexually mature. In females, however, clear immatures were present, and a 

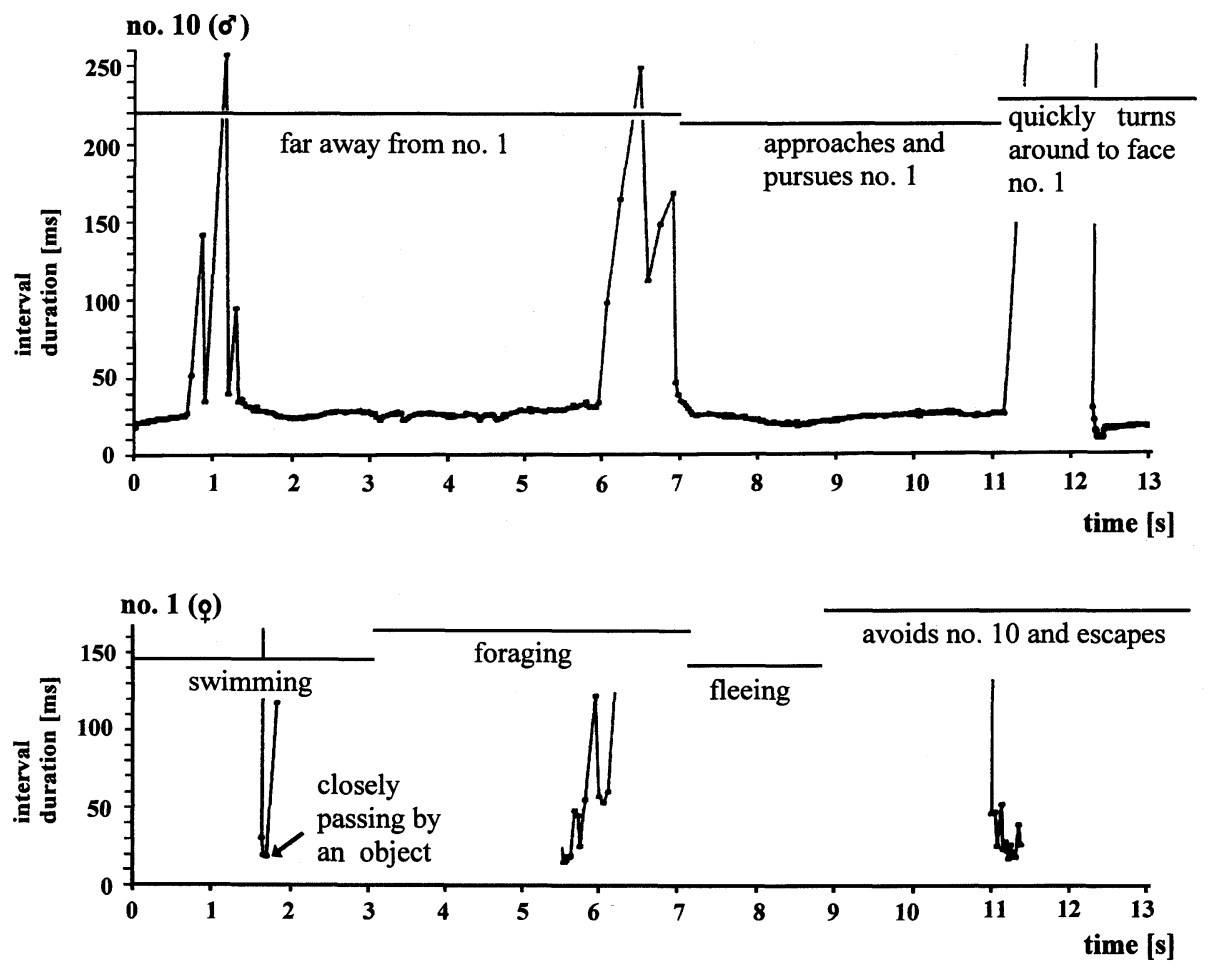

Fig. 6: Concurrent discharge activities with discharge breaks as observed in a submissive fish (fish no. 1, female) during the approach of the aggressive, dominant fish no. 10 (male). Ordinates and abscissae as in Fig. 3

development of a sexual dimorphism in EOD waveform with further growth cannot be excluded.

Alternatively, a greater variance of a male character was shown to represent a group trait in a certain clade of stalk-eyed flies that also includes members with a sexual dimorphism. A greater variability of male traits probably has facilitated the evolution of male accentuated characters (BURKHARDT \& DE LA MOTTE 1985, 1988); a similar situation could be present in the genus Marcusenius. In fact, in a recently studied wild population of $M$. macrolepidotus from southern Africa, EODs were found to be sexually dimorphic (KRAMER 1996; VAN DER BANK \& KRAMER 1996); during puberty the duration of male EODs increases up to 11.5 times compared with the average duration for juveniles, whereas that of females does not change (KRAMER 1997).

Marcusenius senegalensis is a facultatively schooling fish. In the wild, temporary aggregations such as those observed in our aquaria would probably improve effective exploitation of resources and reduce predator pressure (nocturnal predators include for instance the electric catfish, Malapterurus electricus, the sharptooth catfish, Clarias gariepinus, the Nile knifefish, Gymnarchus niloticus, fish owls, bats and crocodiles), based on reciprocal altruism (TRIVERS 1971). For example, members of the 'surface-flotation' groups can prey on flying insects fallen onto the water surface and air-breathing water insects that were detected by 

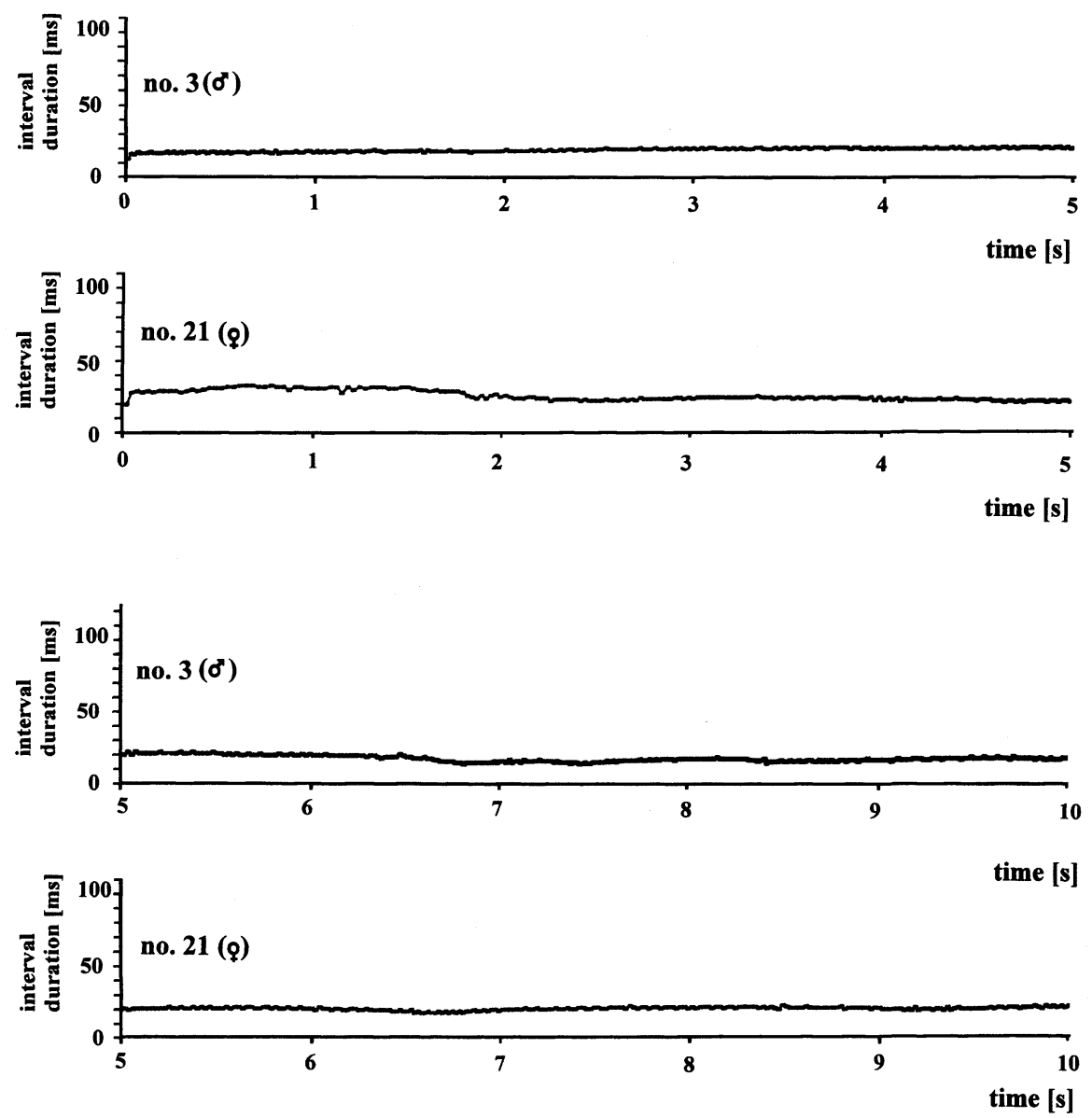

Fig. 7: Courtship: concurrent discharge activity of a dominant male (fish no. 3) and a subdominant female (fish no. 21) while swimming around each other without any aggression. (The lower panel is the continuation of the upper.) Ordinates and abscissae as in Fig. 3

single group members within a very short time. The significance of electric discharges for group cohesion has already been demonstrated for Marcusenius cyprinoides in the laboratory (MOLLER 1976), where the fast one-by-one swimming was described in similar form and was called 'single-file-swimming'.

Aggregations as tight foraging schools were accompanied by high-frequency discharge patterns. Such patterns are also known from 'probing motor acts' (TOERRING \& BELBENOIT 1979) in isolated mormyrids. Probing motor acts enable fish to explore nearby objects by active electrolocation, high-frequency pulse-sequences guaranteeing a good sampling rate. Foraging resembles a kind of probing motor act ('chin probing' in Gnathonemus petersii-SERRIER \& MOLLER 1981). Besides their function in electrolocation, these discharge patterns obviously have an attractive effect on neighbours. A similar case 

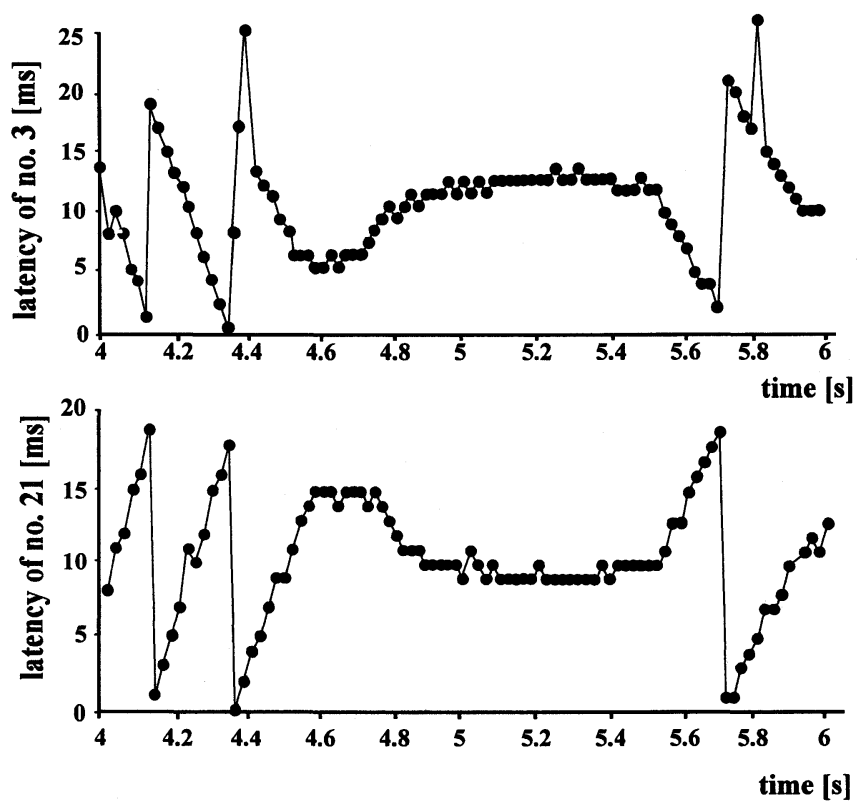

Fig. 8: Discharge latencies for a period of locking into the same discharge rate in a pair of Marcusenius senegalensis as shown in Fig. 7. Note period of preferred latency responses from about $4.8 \mathrm{~s}$ to $5.5 \mathrm{~s}$. Ordinates: discharge latency (ms) of one fish to the EODs of the other [ms]; Abscissae: time [s] according to the abscissa in Fig. 7.

seems to be the 'single-file swimming'. The high swimming speed requires a raised sampling rate for active electrolocation that induces group members to follow.

During fast flight behaviour of single fish, discharge bursts occur. On the other hand, the escape of whole groups is triggered by the fast escape of a single member. Therefore, an early predator alarm (SMITH 1992) based on electrocommunication seems to exist. Predator avoidance by information transfer within a school is called the 'Trafalgar effect' (PITCHER \& PARRISH 1993). Furthermore, the unpredictable rearrangement of members within shoals during nocturnal surface flotation and daytime foraging at the ground, and fast one-by-one darting between shelters (single-file swimming), could lower the predators' success rate according to the 'confusion effect' (PITCHER \& PARRISH 1993).

There is evidence for loose nocturnal aggregations in the field which serve to exploit resources in groups (MOLLER et al. 1979). The individual distances in our loose nocturnal shoals were within the range of electrocommunication (up to $157 \mathrm{~cm}$ at $52 \mu \mathrm{S} / \mathrm{cm}$ water conductivity) determined in the mormyrid Brienomyrus niger in the laboratory (SQUIRE \& MOLLER 1982). The recognition of typical inter-EOD interval patterns as emitted during swimming (species-recognition) and the synchronization of intervals between near neighbours seems to play a role in such slowly moving associations. A statistically significant preference for discharge patterns as emitted by conspecifics during nocturnal swimming, rather than those from a closely related species, has been shown in the mormyrid Campylomormyrus rbynchophorus by play-back experiments (KRAMER \& KUHN 1994). 
Backward swimming during the approaching phase of an agonistic conflict could be derived from a special kind of probing motor act - the 'exploratory backward swimming' (TOERRING \& BELBENOIT 1979). By ritualization it could function as an aggressive threat behaviour, but it also enables the fish to escape swiftly in the opposite direction. The stereotyped threat patterns of repeated bursts were only performed during typical threat displays like distance threat and antiparallel display, resembling the RAL display (regular alternation of high and low rate) shown by female Pollimyrus adspersus (isidori) signalling unwillingness to continue spawning (BRATTON \& KRAMER 1989). According to classical ethological theory, threat behaviour signals a high level of both attack and fleeing tendencies (BAERENDS 1975). By ritualization the threat discharge pattern could have evolved from regularly alternating 'attack' and 'flight' discharge sequences. The longer intervals between the bursts might result from irregular discharge patterns as displayed by stationary fish, or could be derived from the discharge breaks of a subdominant fish.

Threat discharge patterns of some other mormyrid species are known. Aggressive males of Pollimyrus adspersus (isidori) discharge by long, high-frequency bursts (BRATTON \& KRAMER 1989). In agonistic contests, Gnathonemus petersii shows regularly alternating intervals of 8 and $16 \mathrm{~ms}$ or regular interval patterns of $16 \mathrm{~ms}$ (BAUER 1972; BELL et al. 1974; KRAMER 1974; KRAMER \& BAUER 1976). In subdominant, flight-motivated Gnathonemus petersii, short discharge breaks occur (BELL et al. 1974; KRAMER 1976b) that resemble the regular breaks in Marcusenius senegalensis' threat patterns.

Subdominant fish of an established pair were in an obvious conflict with regard to their electrical activity: on the one hand they had to be 'electrically silent' so as not to attract the attacks of the dominant fish. On the other hand they temporarily discharged during foraging or passing nearby objects, probably for active electrolocation - at the risk of being attacked. Discharge cessations also have been observed in groups of Marcusenius macrolepidotus and were called 'social silence' (GRAFF 1986 as cited in MOLLER 1995) where 'social silence' of the whole group was elicited by the increased EOD activity of one fish. This is in accordance with our results (increased EOD rate of the dominant fish and concurrent discharge cessation of the subordinate fish) and suggests the importance of 'social silence' for the hierarchy in groups. Long discharge cessation is also known from subdominant Gnathonemus petersii associated with a reduced rate of being attacked (KRAMER 1976a,b). The short discharge breaks by an approaching dominant $M$. senegalensis are comparable to the discharge breaks of aggressive $P$. adspersus (isidori) chasing a subdominant conspecific (BRATTON \& KRAMER 1989). Probably these displays are used as an aggressive threat discharge pattern.

The highly regular EOD interval series displayed during courtship behaviour were similar to the discharge patterns of probing motor acts (same range of interval lengths). The motor displays resembled the 'exploratory backward swimming'. This suggests an evolutionary relationship between courtship displays and probing motor acts; this may seem less strange when considering that courtship takes place at night. At the same time, an important role of discharge latencies cannot be excluded. From $P$. adspersus (isidori) a sexual dimorphism of latency-related discharge behaviour is known, males preferring latencies of about $12 \mathrm{~ms}$ and females avoiding them (LÜCKER \& KRAMER 1981). Similar preferred latencies were seen in both sexes in $M$. senegalensis during a short courtship episode (Fig. 8). 


\section{Literature Cited}

BAERENDS, G. P. 1975: An evaluation of the conflict hypothesis as an exploratory principle for the evolution of displays. In: Function and Evolution in Behaviour. Essays in Honour of Niko Tinbergen (BAERENDS, G.P., BeER, C. \& MANNING, A., eds). Clarendon Press, Oxford. pp. 187-227.

BAUER, R. 1972: High electrical discharge frequency during aggressive behaviour in a mormyrid fish, Gnathonemus petersii. Experientia 28, 669-670.

- - \& KRAMER, B. 1974: Agonistic behaviour in mormyrid fish: latency relationship between electric discharges of Gnathonemus petersii and Mormyrus rume. Experientia 30, 51-52.

BELL, C. C., BRADBURY, J. \& Russell, C. J. 1976: The electric organ of a mormyrid as a current and voltage source. J. Comp. Physiol. 110A, 65-88.

- - MYERS, J. P. \& RUSSELL, C. J. 1974: Electric organ discharge patterns during dominance related behavioural displays in Gnathonemus petersii J. Comp. Physiol. 92, 201-228.

BLAKE, B.F. 1977: Aspects of the reproductive biology of Hippopotamyrus pictus from Lake Kainji, with notes on four other mormyrid species. J. Fish Biol. 11, 437-445.

BRATTON, B. O. \& KRAMER, B. 1988: Intraspecific variability of the pulse-type discharges of the African electric fishes, Pollimyrus isidori and Petrocephalus bovei (Mormyridae, Teleostei), and their dependence on water conductivity. Exp. Biol. 47, 227-238.

- _ \& — - 1989: Patterns of the electric organ discharge during courtship and spawning behaviour in the mormyrid Pollimyrus isidori. Behav. Ecol. Sociobiol. 24, 349-368.

BURKARDT, D. \& DE LA MOTTE, I. 1985: Selective pressures, variability and sexual dimorphism in stalk-eyed flies (Diopsidae). Naturwissenschaften 72, $204-206$.

- _ \& - 1988: Big antlers are favoured: female choice in stalk-eyed flies (Diptera, Insecta), field collected harems and laboratory experiments. J. Comp. Physiol. 162A, 649-625.

GossE, J. P. 1984: Mormyriformes. In: Check-list of the Freshwater Fishes of Africa. (DAGET, J., GossE, J.P. \& Thys VAn Den Audenaerde, D.F.E., eds). Office Rech. Sci. Tech. Outre-Mer (ORSTOM), Bondy / Mus. R. Afr. Cent. (MRAC), Tervuren. pp. 63-124.

GRAFF, C. 1989: Firing activity of the weakly electric fish Marcusenius macrolepidotus (Mormyridae, Teleostei): logarithmic repartition of inter-pulse intervals, and sequential inequality testing. Behaviour 109, 258-284.

HOPKINS, C. D. 1981: On the diversity of electric signals in a community of mormyrid electric fish in West Africa. Am. Zool. 21, 211-222.

- - 1988: Neuroethology of electric communication. Annu. Rev. Neurosci. 11, 497-535.

KOLDING, J., TiRASIN, E. M. \& KARENGE, L. 1992: Growth, mortality, maturity and length-weight parameters of fishes in Lake Kariba, Africa. NAGA, The ICLARM Qu. 15, 39-41.

KRAMER, B. 1974: Electric organ discharge interaction during interspecific agonistic behaviour in freely swimming mormyrid fish. A method to evaluate two (or more) simultaneous time series of events with a digital analyser. J. Comp. Physiol. 93, 203-235.

- - 1976a: The attack frequency of Gnathonemus petersii towards electrically silent (denervated) and intact conspecifics, and towards another mormyrid (Brienomyrus niger). Behav. Ecol. Sociobiol. 1, 425-446.

- 1976b: Flight-associated discharge patterns in a weakly electric fish, Gnathonemus petersii (Mormyridae, Teleostei). Behaviour 59, 88-95.

- 1979: Electric and motor responses of the weakly electric fish, Gnathonemus petersii (Mormyridae), to playback of social signals. Behav. Ecol. Sociobiol. 6, 67-79.

- 1990: Electrocommunication in Teleost Fishes: Behavior and Experiments. Springer-Verlag, Berlin.

- 1994: Communication behaviour and sensory mechanisms in weakly electric fishes. In: Advances in the Study of Behaviour, Vol. 23 (SLATER, P.J.B., RosenBlatT, J.S., SNOwdON, C.T. \& MilinSKI, M., eds). Academic Press, San Diego (CA). pp. 233-270.

- 1996: Electroreception and Communication in Fishes. (Progress in Zoology, Vol. 42.) Gustav-FischerVerl., Stuttgart.

- 1997: Electric organ discharges and their relation to sex in mormyrid fishes. Naturwissenschaften, 84, 119-121.

—— \& BAUER, R. 1976: Agonistic behaviour and electric signalling in a mormyrid fish, Gnathonemus petersii. Behav. Ecol. Sociobiol. 1, 45-61.

- - \& KUHN, B. 1993: Electric signalling and impedance matching in a variable environment: the electric organ of a mormyrid fish actively adapts to changes in water conductivity. Naturwissenschaften $\mathbf{8 0}, 43-46$.

- _ \& - 1994: Species recognition by the sequences of discharge intervals in weakly electric fishes of the genus Campylomormyrus rhynchophorus (Mormyridae, Teleostei). Anim. Behav. 48, 435- 445. 
—— \& LÜCKER, H. 1990: Species recognition by EOD interval pattern. In: Electrocommunication in Teleost Fishes: Behavior and Experiments (KRAMER, B., ed.). Springer-Verl., Berlin. pp. 157-170.

LANDSMAN, R. E. 1995: Sources of plasticity in behaviour and its physiology: sex, hormones, environment and the captivity model. In: Electric Fishes: History and Behavior (MOLLER, P., ed.). Chapman \& Hall, London. pp. 303-343.

Lévêque, C., Paugy, D. \& Teugels, G. G. 1990: Faune des Poissons d'Eaux Douces et Saumâtres de l'Afrique de l'Ouest. ORSTOM/MRAC, Paris.

LISSMANN, H. W. 1958: On the function and evolution of electric organs in fish. J. Exp. Biol. 35, 156-191.

LORENZ, R. J. 1988: Grundbegriffe der Biometrie (2nd Ed.). Gustav-Fischer-Verl., Stuttgart.

LÜCKER, H. \& KRAMER, B. 1981: Development of a sex difference in the preferred latency response in the weakly electric fish, Pollimyrus isidori (Cuvier et Valenciennes) (Mormyridae, Teleostei). Behav. Ecol. Sociobiol. 9, 103-109.

MOLLER, P. 1976: Electric signals in schooling behaviour in a weakly electric fish, Marcusenius cyprinoides (Mormyriformes). Science 193, 697-699.

_ - 1995: Electric Fishes: History and Behavior. Chapman \& Hall, London.

- - Serrier, J., Belbenoit, P. \& Push, S. 1979: Notes on ethology and ecology of the Swashi River mormyrids (Lake Kainji, Nigeria). Behav. Ecol. Sociobiol. 4, 357-368.

PITCHER, T. J. \& PARRISH, J. K. 1993: Functions of shoaling behaviour in teleosts. In: Behaviour of Teleost Fishes (2nd Ed.) (PITCHER, T.J., ed.). Chapman \& Hall, London. pp. 363—427.

SERRIER, J. \& MOLLER, P. 1981: Social behaviour in mormyrid fish (Mormyriformes, Pisces): short and long term changes associated with repeated interactions. In: Sensory Physiology of Aquatic Lower Vertebrates. Adv. Physiol. Sci., Vol. 31 (SzABo, T. \& CZEH, G., eds). Pergamon Press / Akad. Kiado, Budapest. pp. $221-233$.

SMITH, R. J. F. 1992: Alarm signals in fishes. Rev. Fish Biol. Fish. 2, 33-63.

SQUIRE, A. \& MOLLER, P. 1982: Effects of water conductivity on electrocommunication in the weak-electric fish Brienomyrus niger (Mormyriformes). Anim. Behav. 30, 375-382.

TAKASHIMA, F. \& HiBIYA, T., eDs 1995: An Atlas of Fish Histology. Normal and Pathological Features (2nd Ed.). Fischer Verl., Stuttgart, New York.

TOERRING, M. \& BELBENOIT, P. 1979: Motor programme and electroreception in mormyrid fish. Behav. Ecol. Sociobiol. 4, 369-379.

TRIVERS, R. L. 1971: The evolution of reciprocal altruism. Qu. Rev. Biol. 46, 35-57.

VAN DER BANK, F. H. \& KRAMER, B. 1996: Phylogenetic relationships between eight African species of mormyriform fish (Teleostei, Osteichthyes): resolution of a cryptic species, and reinstatement of Cyphomyrus Myers 1960. Biochem. Syst. Ecol. 24, 275-291.

Received: January 5, 1996

Accepted: November 22, 1996 (W. Wickler)

Note added in proof: Fish are stored at the Zoologische Staatssammlung, Münchhausenstr. 21, D-81247 Munich, Germany. Museum catalogue numbers are ZSMI 28534-28553. 